\title{
Collusion Theory in Search of Robust Themes: A Comment on Switgard Feuerstein's Survey
}

\author{
KAI-UWE KÜHN \\ kukuhn@umich.edu \\ Department of Economics, University of Michigan, 258 Lorch Hall, 611 Tappan St., Ann Arbor, \\ Michigan 48109, USA
}

\begin{abstract}
In this comment the survey by Feuerstein is taken as a point of departure to discuss some of the key challenges facing collusion theory in its application to competition and trade policy. The main issue is one of robustness. It is discussed that the popular use of equilibria with Nash reversion leads to highly non-robust results and contrasts this with a recent approach aimed at detecting robust implications of collusion models. The comment also addresses the challenges posed by renegotiation and tacit collusion.
\end{abstract}

Keywords: collusion, robustness, Nash reversion, optimal punishments, renegotiation, tacit collusion, competition policy

JEL Classification: L13, L41

In her survey, Switgard Feuerstein covers an impressively broad range of subjects related to the application of collusion theory to industrial organization and international trade. Given the magnitude of the literature and the sheer number of - often contradictoryresults this is an enormous task. The survey does a great service by highlighting some of the issues in this literature that are important for the practical policy application of the theory. For example, Feuerstein rightly points out how little the economic literature has had to say about how agreement on a collusive equilibrium is achieved and that this is a problem for policy advice. ${ }^{1}$ She also puts at the center of her survey models of collusion in homogeneous goods markets with capacity constraints and the specific insights arising from such models. Given the importance of capacity constraints in many collusion cases this theory should indeed be utilized much more frequently in practical antitrust analysis. Finally, the emphasis on evidence from empirical and experimental studies on collusion correctly calls the attention to the fact that our knowledge about collusion is not based on theorizing alone.

The issues I want to raise in my comments are broader and go to the heart of our use of collusion theory for applied industrial organization. Both the strength and the weakness of this survey is that it accurately conveys how collusion theory is applied in a large part of the industrial organization literature: Little attention is given to whether results are derived under Nash reversion or under optimal punishments. ${ }^{2}$ Policy recommendations

1 I discuss this issue at length in Kühn (2005a).

2 Nash reversion (sometimes called "trigger strategies") refers to strategies that punish deviations from an agreed collusive price by reverting to the one shot Nash equilibrium forever. With optimal punishment strategies, in contrast, firms switch to the worst possible continuation equilibrium within the set of (subgame perfect) equilibria. Typically such punishments are harsher than Nash reversion. They also have a very simple structure: Firms agree on behavior that is maximally aggressive after a deviation for the shortest period of time possible. After that they return to some collusive equilibrium. (see Abreu et al., 1990). 
are often made without citing the particular assumption made. Very little research time has been spent on the most crucial issue for policy purposes: the robustness of results and the relative importance of different effects. Furthermore, the literature has persistently ignored that the issue of tacit collusion raises deep challenges for our understanding of coordinated conduct that are of central concern for competition policy.

In this comment I will first challenge the ubiquitous use of models that limit equilibrium punishments to Nash reversion. Contrary to the impression created in Feuerstein's paper (in particular in the appendix), there are no fundamental difficulties in completely characterizing the set of all equilibria without resorting to such arbitrary assumptions about punishments. But dispensing with arbitrary assumptions about punishments does make a difference. I will discuss below that Nash reversion leads to highly non-robust results even when the comparative statics on the full equilibrium set would allow one to draw robust conclusions about collusion. I will also discuss that considering the full equilibrium set is often necessary to address some of the more interesting policy issues. Second, I will outline the robust themes that come out of existing collusion theory. The third topic I will raise concerns the issue of renegotiation. I will outline the arguments why certain issues in collusion theory cannot be resolved without a model of renegotiation. In these areas current theory should essentially be ignored for policy making since it gives little guidance on likely outcomes. The fourth theme is the most troubling of all. The literature has made virtually no progress on dealing with the issue of tacit collusion. However, this is a central issue that needs to be resolved for policy purposes, especially in the context of coordinated effects analysis in merger cases. ${ }^{3}$

\section{Why we should not rely on Nash reversion}

We have known for a long time that there is typically a large number of equilibria in infinitely repeated games. Indeed, this multiplicity of equilibria is necessary for any theory of collusion because credible punishments require the switch from a high profit continuation equilibrium to a low profit continuation equilibrium. ${ }^{4}$ Given this multiplicity of equilibria, the only consistent way of doing comparative statics of collusion is to analyze how the set of possible equilibria changes as the environment is changed. This may appear a formidable task, but it has been greatly facilitated by the work of Abreu et al. (1990). They show that optimal punishment strategies exhibit "bang-bang" behavior, i.e., they can be characterized by only looking at the extremal points of the equilibrium value set. Under optimal punishments any deviation leads to a switch to the worst possible equilibrium from the point of view of the deviating firm. Abreu et al. show that the analysis of optimal punishments is critical to deriving the full equilibrium set: they not only can sustain any feasible outcome, but they are also necessary to sustain some outcomes.

3 See (Kühn 2005a) for a more extensive analysis of this and the other issues raised in this note from the view of coordinated effects analysis in merger policy.

4 This is the reason why collusion can be feasible in finitely repeated games. What is necessary is that the stage game has multiple equilibria. (see Benoit and Krishna, 1985). 
It has also been demonstrated that comparative statics can sometimes be done analytically on the full equilibrium value set. For example, when the discount factor is increased the new set of equilibrium outcomes strictly contains the old (Abreu et al., 1990). Or (under imperfect monitoring), the set of equilibrium outcomes strictly expands when demand is less volatile (Kandori, 1992). The latter is an example of a robust result on the role of monitoring that can be used for policy formulation.

The technical difficulty of deriving such results has led researchers to look for shortcuts. Resorting to Nash reversion as the punishment path is such a shortcut. Another is to focus on symmetric optimal punishments in symmetric games. These equilibria are derived using the logic of optimal punishments but restricting equilibrium strategies to be symmetric. Such shortcuts can only be justified if the analysis leads to qualitatively the same results as the analysis of the full equilibrium value set. ${ }^{5}$ However, this is not the case for collusion under Nash reversion.

Kühn and Rimler (2005) have shown in an unpublished manuscript that there is a reason why symmetric optimal punishment equilibria in symmetric models achieve robust results while Nash reversion does not. To do this they consider a general product differentiation model with a one dimensional product differentiation parameter. ${ }^{6}$ They can generally analyze the model at the limit as product differentiation goes to zero. Under optimal punishments, the punishment price at the homogeneous goods limit is strictly below marginal cost. Under Nash punishments the punishment price is just at marginal cost. Hence, as some slight product differentiation is introduced, there is a first order reduction in the punishments in the Nash reversion case. However, with optimal punishments, the punishment price remains strictly below marginal cost, so that the best profit a firm deviating from punishments can obtain is virtually unchanged at zero. In other words, the change of profits in the punishment equilibrium from a slight increase of product differentiation is of second order. Since the impact on the incentives to deviate from a collusive price is of first order (there is strictly less of an incentive to undercut), this effect strictly dominates, generating the unambiguous result that product differentiation facilitates collusion.

Under Nash reversion the effects on the incentives to deviate from collusion and the impact on punishment profits remain of the same order. Kühn and Rimler (2005) show that it depends on the functional form of demand and even on the parametrization of a specific demand function what the outcome of the comparative statics with respect to the degree of product differentiation is. The result by Deneckere (1983), cited by Feuerstein as one of the "basic results" in collusion theory, is therefore highly non-robust. Indeed,

5 There is no intrinsic interest in Nash reversion itself. Such strategies are not particularly simple relative to optimal punishments (which are very simple) and there is no other feature that singles out Nash reversion except for its analytical convenience.

6 In all discussions in this paper I only consider price setting firms. One of the reasons that I believe we should not put any emphasis on analysis under quantity setting behavior is that we can only understand such behavior as a reduced form model for sequential capacity and price decisions. But then we should be analyzing a collusion model with capacity and price decisions. The reduced form quantity setting model will in most cases lead to very misleading results. 
the only robust result for product differentiation and collusion under Nash reversion is for a sufficiently large number of firms. Then punishments are always so close to marginal cost pricing that the effect on the incentives to deviate must dominate, again contradicting the Deneckere result.

There are two further profound lessons for robustness from this analysis. First, for any parameter change, the impact of the relative importance on the incentive to deviate from collusion and the impact on optimal punishments can be obtained from the limiting homogeneous goods model. This means that comparative statics obtained in homogeneous goods models will be robust to the introduction of product differentiation. Second, in symmetric models, the analysis of symmetric punishment strategies fully captures the qualitative impact on the full equilibrium value set. The same analysis of relative order of magnitude on the two effects implies that the equilibrium value set strictly expands with an increase in product differentiation from the homogeneous good limit. Hence, all of the qualitative analysis is captured in the analysis of symmetric optimal punishment strategies.

In asymmetric models, symmetric optimal punishment strategies will generally not capture the impact of a change in a parameter on collusion well. The fundamental reason for this is that such models often will not have the property that the equilibrium value sets for different parameter values are nested. ${ }^{7}$ In such cases only numerical models can fully capture the comparative statics. However, Abreu et al. (1990) again have given us the tools for such an analysis. The algorithm they develop is easily implemented for such models as demonstrated in Kühn (2004) in the context of coordinated effects analysis and Kühn and Rimler (2005) in an asymmetric cost model. A combination of analytical and numerical tools are therefore available that imply that there is no excuse for analyzing collusion under Nash reversion. Clearly, policy makers should not trust advice that is given on the basis of models with Nash reversion.

\section{Robust themes in collusion theory}

Although applied collusion theory may appear like a jumble of disjoint results, there are in fact themes emerging that are theoretically robust and empirically supported. The three most important of these themes are the role of imperfect observability and uncertainty, the role of anticipated intertemporal fluctuations of any kind, and the impact of asymmetries (or heterogeneity) between firms.

First, the work of Abreu et al. (1990) together with Kandori (1992) has firmly established that imperfect monitoring will generate the need for price wars in the presence of demand uncertainty. Unanticipated demand shocks lead to punishment phases in equilibrium because they cannot be distinguished from actual cheating on a collusive agreement. The higher demand uncertainty under imperfect monitoring, the

7 In such a case one cannot state that for one parameter value more collusive outcomes are possible than for others. There is therefore no unambiguous way to state whether collusion gets easier or more difficult. One then has to close the model by assuming some equilibrium selection rule like bargaining (see Kühn and Rimler, 2005). 
more difficult collusion is. A focus on monitoring ability and uncertainty, or in policy speak "transparency" should therefore be a central ingredient for policies against collusion. Indeed, the recent "Airtours judgement" by the European Court of First Instance has firmly established this as a key policy criterion for the assessment of joint dominance in merger cases. ${ }^{8}$

The second basic principle is that anticipated changes in profitability will also have systematic effects on collusion. If future expected profitability is higher, then undercutting is less attractive because the loss from future punishments is (relatively) more severe. Reversely, if profits today are unusually high relative to expected future profits, collusion is more difficult to sustain. This is the basic principle that underlies Rotemberg and Saloner (1986), Haltiwanger and Harrington (1991), and Bagwell and Staiger (1997). This principle underlies the results on exchange rate fluctuations by Meckl (1996) and Feuerstein (2004). It also explains the "surprising" result that collusion is more difficult with transitory exchange rate fluctuations than for permanent changes in the exchange rate (Cabral and Mello, 1997). Transitory exchange rate fluctuations lead to anticipated changes in demand that are frequently downward, which makes collusion harder. ${ }^{9}$

Note that these robust results contradict the standard rules of competition authorities that act on the assumption that there is more danger of collusion when the market declines. But the empirical evidence is at least consistent with the theory. Dick (1996b) has shown that collusion is more likely to break down in business cycle downturns and Borenstein and Shepard (1996) have shown that anticipated demand movements have the impact predicted by the theory.

The third principle is the impact of asymmetries or heterogeneity on the ability to collude. A recent literature on the coordinated effects of mergers, pioneered by Compte et al. (2002), has focused on asset based cost asymmetries (Compte et al., 2002; Vasconcelos, 2004), and product line asymmetries (Kühn, 2004). But the literature on asymmetries is much older including literature on asymmetries in discount factors (Harrington, 1989) and costs (among others Harrington (1991), Rothschild (1999)). The basic insight in all of this literature is that heterogeneity in incentives means that the firms with the most extreme incentives most limit the ability to collude. Hence, asset redistributions that reduce the extremes in incentives will always aid collusion. This is a very robust result although there are some types of asymmetries that will not have such an impact.

There are other robust results that may surprise economists used to the literature. For example, once one focuses on the full equilibrium set it is a robust result that collusion is

8 The Airtours case (case T-349/99 Airtours) is now the classic case for the application of joint dominance arguments in merger cases. It focuses the analysis on the incentive compatibility of collusion and the feasibility of monitoring. The Court of First Instances thus clearly bases the joint dominance concept on the key elements of collusion theory. See Kühn (2002) for a more detailed discussion.

9 All of the theories work just as well if one considers cost shocks. It is unfortunate that these results are still presented as a debate of whether price wars occur in booms or busts. It is questionable that the price shading in optimal collusion in Rotemberg and Saloner (1986) and the other papers should be considered as price wars at all. They certainly do not exhibit the persistence properties of price wars in the imperfect monitoring literature. Over this discussion the unifying mechanism of profit movements over time tends to get lost. 
facilitated by product differentiation. Again this is a theoretical fact that contradicts conventional competition policy wisdom. However, there is now empirical evidence (Dick, 1996a) supporting it. There is also a robust result that cross-share holdings facilitate collusion. This may also come as a surprise to economists thinking in the framework of Nash reversion. We know that cross-share holdings reduce the incentive to deviate from collusion. But by the same argument they increase the profits in a one shot Nash equilibrium. However, once we go to optimal punishments the picture changes dramatically. Suppose you have punishments below marginal cost. If a firm with crossshare holdings tries to deviate by setting a higher price it will still not escape the losses other firms incur that it has a cross-share holding in. Indeed, punishments can yield continuation values of less than zero because a firm cannot escape punishments by deviating. In other words, cross-share holdings can lock firms into severe punishments after deviation. As a result even small cross-share holdings substantially facilitate collusion (see Kühn and Rimler, 2005). Thinking in terms of Nash reversion simply leads the researcher astray in this case.

Up to this point I have been focused on the surprising robustness of results in collusion theory once we do not make arbitrary restrictions on the equilibrium set. But there are also some surprisingly non-robust statements about collusion theory. The most important one is the first basic result Feuerstein spells out in her paper: The larger the number of firms, the more difficult collusion. As she herself points out later on, this result is surprisingly non-robust in settings with capacity constraints. Indeed, one can show (see Kühn, 2005b) that in any model with constant returns to scale (but non constant marginal costs), a redistribution of existing capacities to a larger number of firms will always facilitate collusion. However, one can also show that there is a simple condition on the relative size of market demand to market capacity that bounds the degree of collusion that can be obtained. What this shows is that, even where there is non-robustness in the literature, useful robust results can still be derived. Such a focus on robustness is however still rare in the collusion literature.

\section{The importance of renegotiation}

In this section I will argue that collusion theory can be seriously misleading when one does not consider the possibility of renegotiating away from previously agreed punishments. The best example why this is important is the consideration of entry in a collusion context. Contrary to empirical facts (see Levenstein and Suslow, 2004) and economic intuition, entry does not necessarily have much of an impact on collusion in theory. The reason is simple (see Stenbacka, 1990): A collusive agreement can always contain a clause that any entry should be regarded as a deviation from the collusive agreement. If firms can push profits down to the level of entry costs (which is always possible in a homogeneous goods model), no entry will ever occur-whatever the previous number of firms. Friedman and Thisse (1994) correctly argue that firms should recognize that after entry the situation has changed. It would be better to bring the entrant into the fold of colluding firms. Friedman and Thisse try to escape modeling 
renegotiation by imposing ad hoc constraints on the strictness of punishments. However it is not clear that such ad hoc restrictions can have any predictive power. The only consistent way is to model renegotiation explicitly and fully explore the set of renegotiation proof equilibria.

But once one acknowledges the need to look at renegotiation when there is entry, it is clear that this argument applies to any setting in which firms are required to punish harshly. However, there have been substantial difficulties of moving in this direction. Feuerstein correctly points out in the Appendix that renegotiation in the spirit of Farrell and Maskin (1989) and Van Damme (1989) appears fairly intractable for applied work. The reason is that no collusion can be sustained with symmetric punishments so that there is no simple short cut like optimal symmetric punishment equilibria in the standard collusion model. The notion of renegotiation developed in these papers also has conceptual problems. Firms renegotiate to equilibria that cannot be sustained if the possibility of such renegotiation in the future is anticipated. Pearce (1987) has developed a renegotiation model that is free of this problem, allows for symmetric collusive equilbiria and has been extended to general strategies by Abreu et al. (1993).

Of course, once renegotiation is considered the whole question of robustness discussed in the previous section is raised again. Is there any reason to expect that renegotiation proof equilibria have similar comparative statics properties to those currently derived? There is some hope. The logic underlying imperfect observability as a barrier to collusion, the argument about the impact of profitability changes over time, or arguments about heterogeneity between firms will apply just as in the standard model. ${ }^{10}$ This is less clear with some other of the results that currently appear robust. However, it is clear that solid policy advice on collusion needs to tackle the problem of the robustness of results to the introduction of renegotiation.

\section{The tacit collusion problem}

One of the most important issues about coordinated conduct in real markets is the tacit collusion problem. We often claim that collusion theory is applicable to both tacit and explicit collusion, but it is not. The comparisons we make essentially look at the Pareto frontier of the equilibrium value set or selections from it: Feuerstein suggests to look at the equilibrium with the highest industry profits. Harrington (1991), Kühn (2004) and Kühn and Rimler (2005) look at Nash bargaining over the equilibrium value set to close the collusive model. While legitimate, all these approaches effectively look at explicit collusion. We ask what are the strategies that we could possibly support in an agreement and satisfy incentive compatibility, and then we ask which equilibrium could be selected if we talked things out.

Tacit collusion, in contrast, refers to outcomes we should predict when no such communication takes place. The degree of collusion may be severely limited under such 
circumstances simply by concerns about risk dominance (see Kühn, 2001). But then we would like to say something about how risk dominance considerations are changed when the environment changes. Similarly, we have the problem that for tacit collusion to work it is not just necessary to communicate what prices firms want to set, but also what the punishments would be in the case of non-compliance. Can this be learned? And what constraints does learning put on the degree of collusion achievable in equilibrium? All of these questions are wide open, but of critical interest to policy discussions about, for example, the treatment of coordinated effects of mergers. One way forward in this direction is to ask systematic questions about tacit collusion through experimental research. I believe the survey by Feuerstein does a great service to be one of the first that presents the experimental research as an integral part of industrial organization research on collusion.

\section{Conclusions}

The survey by Feuerstein gives an excellent impression of the breadth of applications of collusion theory and its importance to issues in industrial organization and international trade. My comments are an attempt to highlight some extremely robust themes in this literature that are a solid point of departure for policy. At the same tame they also point out some gaping holes in the theory. These holes-whether they concern how agreements are reached, the issue of renegotiation and entry, or the problem of tacit collusion-are currently filled by ad-hoc reasoning and intuition. Compared to the rigorous framework offered by the theory of repeated games this is an unhappy state of affairs.

\section{References}

Abreu, D., Pearce, D., and Stacchetti, E., "Toward a theory of discounted repeated games with imperfect monitoring," Econometrica, vol. 56, pp. 383-396, 1990.

Abreu, D., Pearce, D., and Stacchetti, E., "Renegotiation and symmetry in repeated games," Journal of Economic Theory, vol. 60, pp. 217-240, 1993.

Bagwell, K. and Staiger, R., "Collusion over the business cycle," Rand Journal of Economics, vol. 28, pp. 82-106, 1997.

Benoit, J.-P. and Krishna, V., "Finitely repeated games," Econometrica, vol. 53, pp. 905-922, 1985.

Borenstein, S. and Shepard, A., "Dynamic pricing in retail gasoline markets," Rand Journal of Economics, vol. 27, pp. 429-451, 1996.

Cabral, L. and Mello, A., "Exchange rate expectations and market shares," Economics Letters, vol. 55, pp. 61-67, 1997.

Compte, O., Jenny, F., and Rey, P., "Capacity constraints, mergers and collusion,” European Economic Review, vol. 46, pp. 1-29, 2002.

Deneckere, R., "Duopoly supergames with product differentiation," Economic Letters, vol. 11, pp. 37-42, 1983.

Dick A., "Identifying contracts, combinations and conspiracies in restraint of trade," Managerial and Decision Economics, vol. 17, pp. 203-216, 1996a.

Dick, A., "When are cartels stable contracts," Journal of Law and Economics, vol. 39, pp. 241-283, 1996 b. 
Farrell, J. and Maskin, E., "Renegotiation in repeated games," Games and Economic Behavior, vol. 1, pp. 327-360, 1989.

Feuerstein, S., "Collusion with fluctuating exchange rates: A note," International Journal of the Economics of Business, vol. 11, pp. 107-116, 2004

Friedman, J. and Thisse, J.-F., "Sustainable collusion in oligopoly with free entry," European Economic Review, vol. 38, pp. 271-283, 1994.

Haltiwanger, J. and Harrington, J., "The impact of cyclical demand movements on collusive behavior," Rand Journal of Economics, vol. 22, pp. 89-106, 1991.

Harrington, J., "Collusion among asymmetric firms: The case of different discount factors," International Journal of Industrial Organization, vol. 7, pp. 289-307, 1989.

Harrington, J., "The determination of price and output quotas in a heterogeneous cartel," International Economic Review, vol. 32, pp. 767-792, 1991.

Kandori, M., "The use of information in repeated games with imperfect monitoring," Review of Economic Studies, vol. 59, pp. 581-593, 1992.

Kühn, K.-U., "Fighting collusion by regulating communication between firms," Economic Policy, vol. 16, pp. 167-204, 2001

Kühn, K.-U., "Closing pandora's box? Joint dominance after the airtours judgement," in The Pros and Cons of Merger Control. Swedish Competition Authority, Stockholm, pp. 39-61, 2002.

Kühn, K.-U., "The Coordinated Effects of Mergers in Differentiated Products Markets." CEPR Discussion Paper No. 4769, 2004

Kühn, K.-U., "The Coordinated Effects of Mergers." mimeo. Forthcoming in: Handbook of Antitrust Economics," 2005a.

Kühn, K.-U., "How Market Fragmentation Facilitates Collusion.” mimeo, University of Michigan,” 2005 b.

Kühn, K.-U. and Rimler, M., "The Comparative Statics of Collusion Models. mimeo. University of Michigan," 2005 .

Levenstein, M. and Suslow, V., "Studies of cartel stability: A comparison of methodological approaches," in Grossman, P.Z. (ed.), How Cartels Endure and How they Fail: Studies of Industrial Collusion. Cheltenham and Northampton, MA (Edward Elgar), pp. 9-52, 2004.

Meckl, J., "Market power of firms and exchange rate fluctuations," Journal of Economics, vol. 63, pp. 57-77, 1996.

Pearce, D., "Renegotiation Proof Equilibria: Collective Rationality and Intertemporal Cooperation." Cowles Foundation Discussion paper no. 855, 1987.

Rotemberg, J. and Saloner, G., "A supergame-theoretic model of price wars during booms," American Economic Review, vol. 76, pp. 390-407, 1986.

Rothschild, R., "Cartel stability when costs are heterogeneous," International Journal of Industrial Organization, vol. 17, pp. 717-734, 1999.

Stenbacka, R., "Collusion in dynamic oligopolies in the presence of entry threats," Journal of Industrial Economics, vol. 39, pp. 147-154, 1990.

Van Damme, E., "Renegotiation-proof equilibria in repeated prisoners' dilemma,” Journal of Economic Theory, vol. 47, pp. 206-217, 1989.

Vasconcelos, H., "Tacit collusion, cost asymmetries, and mergers," Rand Journal of Economics, vol. 36, pp. 39-62, 2004. 